\title{
Screening for occupational vitiligo in workers exposed to hydroquinone monomethyl ether and to paratertiary-amyl-phenol
}

\author{
J J O'SULLIVAN AND C J STEVENSON
}

From the Medical Department, ICI Ltd, Mond Division, and the Department of Dermatology, Royal Victoria Infirmary, Newcastle upon Tyne, UK

ABSTRACT Two men reported previously with vitiligo after occupational exposure to hydroquinone monomethyl ether (HMME) have been reviewed after eight years. Repigmentation of significant degree was found in one man and of limited degree in the other. One hundred and sixty-nine men in the same works have been screened with Wood's light for evidence of vitiligo. No cases were found in the 148 men exposed to HMME (colleagues who screened 100 men exposed to HMME in two other factories also found no cases) or in the 129 who had been exposed to paratertiary-amyl-phenol. Loss of light reflection on Wood's light examination was observed in 13 men due to scars or to other skin disorders.

After a report of occupational vitiligo in 54 of 198 men exposed to paratertiary butyl phenol (PTPB), ${ }^{1}$ a fresh look has been necessary at chemical works where depigmentation has been reported. Chivers in $1972^{2}$ reported two cases of occupational leucoderma (vitiligo) after contact with hydroquinone monomethyl ether (HMME), a stabiliser used in the production of vinylidene chloride. It was decided to review the findings in these two men and to screen the work force exposed to this chemical. Men severally or additionally exposed to another chemical capable of depigmenting the skin, paratertiary amylphenol (PTAP), were also included in the survey.<smiles>COc1ccc(O)cc1</smiles>

HMME

(Hydroquinone monomethylether)

Received 4 November 1980 Accepted 2 February 1981

\section{Manufacturing process}

HMME is a fine white crystalline solid, sparingly soluble in water. It can cause irritation of the skin and eyes, so direct contact is avoided on these grounds alone. The material is delivered to the plant in large cardboard containers and is shovelled into a bucket and carried to a mixing drum into which it is tipped to fall through a grill. Lumps of the material can form and require breaking with a metal bar. The operation is carried out in open well-ventilated conditions and gloves and goggles are worn. Apart from the process operators the plant is visited by analysts, electricians, and maintenance workers. Since Chivers's ${ }^{2}$ cases were reported, exposure to the material has been reduced to a minimum.

PTAP has an antiseptic phenolic odour and consists of colourless needles, sparingly soluble in water. It is irritant to the skin and very irritant to the mucous membranes of the eyes and respiratory tract so that masks are always worn in addition to protective clothing. Paper sacks containing the material are transferred by fork lift trucks to a gantry, opened, and the contents transferred to a mixing drum. 


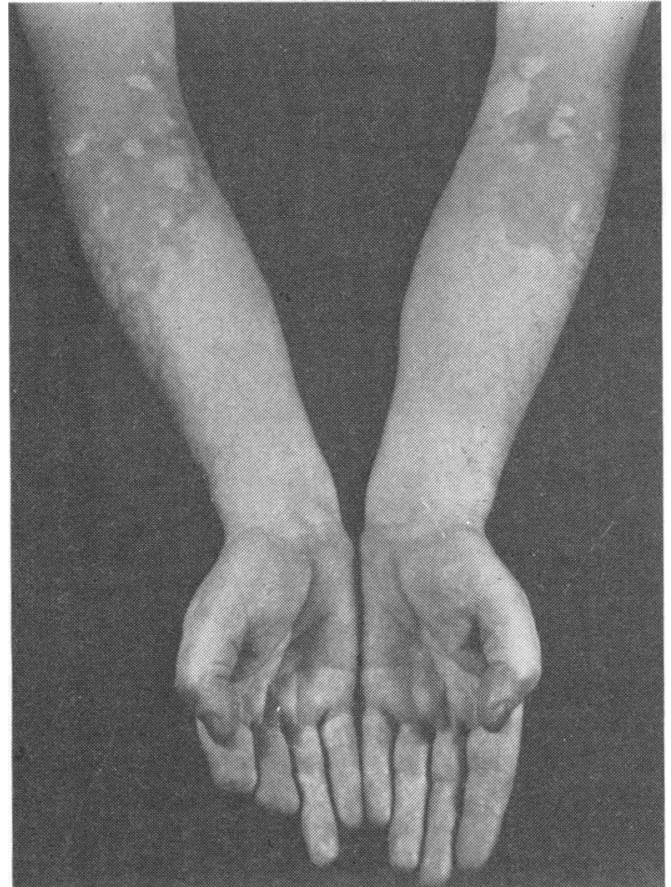

Fig 1 Hands and forearms in 1969.

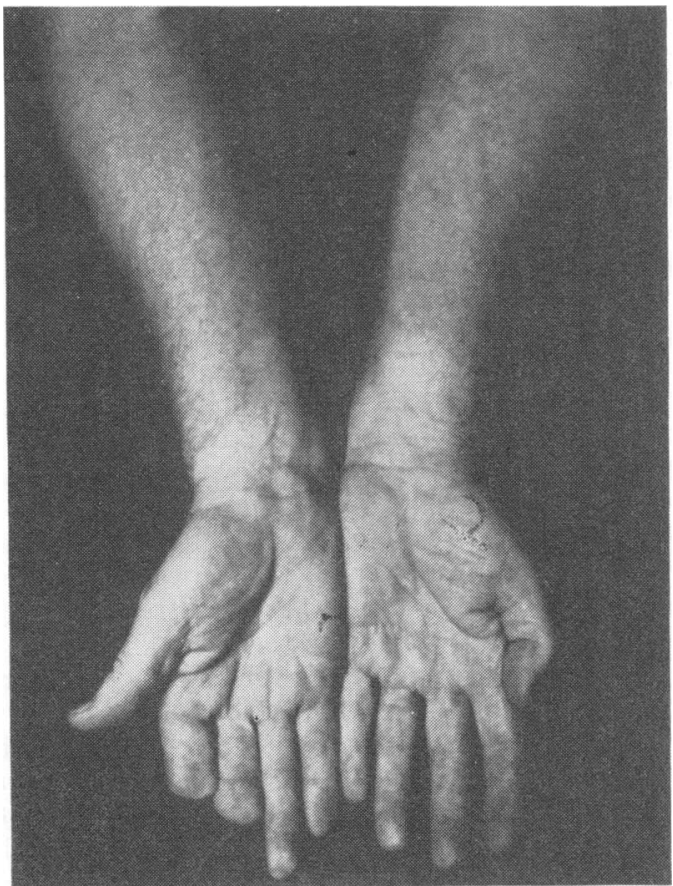

Fig 2 Hands and forearms in 1979 showing obvious repigmentation.
Review of two cases-method and findings

CASE 1

This man now aged 60 had been exposed to HMME as a process worker for about two years when depigmentation was noted on his forearms. In 1972 it affected his hands and forearms but subsequently affected a wider area. Current examination shows vitiligo of the arms, axillae, groins, and feet. Comparison with photographs published by Chivers, ${ }^{2}$ which were taken in 1969, shows obvious repigmentation (figs 1 and 2). Organ specific antibody screen and blood survey including liver function tests are normal. The patient has not worked with PTAP but has continued to work with due precautions with HMME.

CASE 2

This man now aged 45 had been exposed to HMME as a process worker for three years when his vitiligo, drawn to his attention by a colleague, affected his arms and face. Subsequently it has affected his legs. Current examination shows involvement of the neck, arms, shins, and feet. Follicular repigmentation is evident in the affected areas. A blood screen including liver function tests is negative. Gastric parietal antibodies are present, otherwise the organ specific antibody screen is negative.

Occupational vitiligo is indistinguishable from idiopathic vitiligo, and the extent is sometimes not evident without Wood's light examination (this is so at the current examination of case 2). The finding of repigmentation suggests that the vitiligo was occupational in these two men.

\section{Screening programme-material and methods}

In addition to the two men reviewed, men exposed occupationally to HMME, PTAP, or both chemicals were examined. Detailed occupational history including grading of the degree of exposure was noted. (Since Chivers's ${ }^{2}$ cases were reported, however, stringent protective measures have been intensified.) The medical history has included personal and family history of possible autoimmune disease and of medication and alcohol consumption. All men were examined by an occupational physician (JJO'S), both in daylight and in a fully darkened room under Wood's light. In vitiligo the normal or hyperpigmented skin absorbs the radiation from Wood's light, giving a brownish or greyish appearance; areas of non-pigmented skin give a white reflection of the ultraviolet source. Men with suspected increased light reflection under Wood's light were re-examined by a dermatologist (CJS). 
Duration of employment of 169 men exposed to HMME or PTAP

\begin{tabular}{lr}
\hline Duration of employment $(y r)$ of work force \\
\hline$\geqslant 15$ & 20 \\
$10-14$ & 52 \\
$5-9$ & 36 \\
$1-5$ & 57 \\
$<1$ & 4 \\
\hline
\end{tabular}

\section{Results of screening programme}

Of 169 men (process workers (52), fitters and maintenance (17), electricians (28), analysts and technical staff (72)) exposed to HMME or PTAP, 108 had been exposed to both chemicals, 40 to HMME only, and 21 to PTAB only. The frequency and degree of involvement with the chemicals was greatest with process workers, including packers, who numbered 52. Of the 169 men, 108 had been employed on the plant for five years or more and only four for less than one year (table).

Sixty-three men were referred for a second examination. In 50 of these men altered light reflection was due to natural differences in pigmentation in different body areas and in 13 men localised altered light reflection was due to scars or to concomitant inflammatory and scaly skin disease. No case of vitiligo was found. Men who are unaware that they have the complaint have been shown to have vitiligo when exposed to Wood's light, ${ }^{1}$ so that case finding under Wood's light is very accurate.

\section{Discussion}

Although depigmentation has been reported in animals from the topical application of HMME, ${ }^{34}$ apart from the two cases described by Chivers ${ }^{2}$ and re-examined by us no other cases of occupational vitiligo from this chemical have been reported. While the two men could have had natural vitiligo, the nature of the work they were then doing and their subsequent partial recovery of pigmentation in the arms suggests that the vitiligo was occupational.

By contrast with PTPB, which is now widely reported as a cause of occupational vitiligo, ${ }^{2-8}$ failure to find vitiligo in 148 men exposed to HMME suggests that the risk of depigmentation is low with this chemical and that protective measures have been effective in the works. R W Mayes (personal communication, 1979) screened 67 men and D K Lund (personal communication, 1979) screened 33 men who had been exposed industrially to HMME, using Wood's light. No case of vitiligo was found, which is in keeping with our findings.
Occupational depigmentation from PTAP is rare, but is reported by Kahn. ${ }^{9} \mathrm{He}$ described seven hospital workers who had developed depigmentation after using a detergent-germicide containing $0.8 \%$ of PTAP. Four of these patients had pruritus and erythema before depigmentation. Although PTAP is apparently widely used in germicides, no further actual case reports of depigmentation from it have been recorded.

In our series 129 men had been exposed to PTAP. The irritant nature of this chemical in particular may be a safeguard against careless use and contamination. It would appear that similarly hydroquinone can cause depigmentation, but because it is an irritant substance reports of occupational vitiligo from this cause are rare. ${ }^{10}$ We would conclude that HMME and PTAP have a very low potential to cause depigmentation in the industrial setting described.

We thank Dr D P Duffield, divisional medical officer, Mond Division, ICI, Runcorn, for permission to publish this survey; Sister $\mathrm{H}$ Mack, senior nursing officer, and her staff; and the secretarial staff for their help with this project.

\section{References}

${ }^{1}$ James O, Mayes RW, Stevenson CJ. Occupational vitiligo induced by p-tert-butylphenol, a systemic disease? Lancet 1972 ; ii :1217-9.

${ }^{2}$ Chivers CP. Two cases of occupational leucoderma following contact with hydroquinone monomethyl ether. Br J Ind Med 1972;29:105-7.

${ }^{3}$ Brun R. Zur experimentellen Depigmentierung. Journal of the Society of Cosmetic Chemists 1960;11:571-80.

${ }^{4}$ Gellin AG, Maibach HI, Mislaszek MH, Ring M. Detection of environmental depigmenting substances. Contact Dermatitis 1979;5:201-13.

${ }^{5}$ Chamakov NN, Babanov GP, Smirnov AG. Viteliginoid dermatoses in workers of phenol-formaldehyde resin works. Bulletin of Dermatology 1962;4:3. (State Publishing Firm of Medical Literature, Moscow.)

6 Itoh K, Nishitani N, Hara I. A study of cases of leucomelanodermatosis due to phenyl-phenyl compounds. Bulletin of the Pharmacological Research Institute 1968;76: 6-13.

7 Malten KE, Seutter E, Hara I, Nakajuma T. Occupational vitiligo due to paratertiary butyl phenol and homologues. Transactions of the St John's Hospital Dermatological Society London $1971 ; 57: 115-34$.

${ }^{8}$ Calnan CD, Cooke MA. Leucoderma in industry. $J$ Soc Occup Med 1974;24:59-61.

${ }^{9}$ Kahn G. Depigmentation caused by phenolic detergent germicides. Arch Dermatol 1970;102:177-87.

${ }^{10}$ Duffield JA. Depigmentation of skin by quinol and its monobenzyl ether. Lancet 1952 ; i 1164 . 